\title{
Perceived Parental Practices and Quality of Life of Children with Learning Disabilities
}

\author{
R.Moulya ${ }^{1}$, Priti Sirkeck ${ }^{2}$
}

\begin{abstract}
:
Children with Learning Disabilities (LD) in comparison to typically developed children report poorer emotional being, lower self-esteem and satisfaction in their relationships with family and friends. This purposive randomized study used the self-determination theory as a framework to extract the relationship between parental practices and quality of life in children with learning disabilities in a sample of 60 children who have been diagnosed with LD including 30 boys and 30 girls in the age range of 9 years to 12 years. Results revealed parental autonomy support was associated with two quality of life domains, family and Self esteem, in addition to the global quality of life. Hence, autonomy support should be practiced by parents in the home environment to promote self-determination and improve the quality of life in children with LD.
\end{abstract}

Keywords: Learning disabilities, Autonomy support Quality of life.

A child may have academic issues due to many invisible factors and these factors may not be recognised unless the child starts to deteriorate in academic performance. Learning disability remains one of the least understood and the most debated disabling conditions that affect children (Thapa, Aalsvoort \& Pandey, 2008).According to Venkatesan (2010), a child said to be having LD, if the child is "showing discrepancy by more than two grades in reading, writing, spelling and/or arithmetic, despite average to superior general and social intelligence as assessed on standardised tests of intelligence and achievement. This discrepancy should not be due to insufficient school exposure, or because the student is a first generation learner, or has suffered any social and emotional abuse, insult, neglect, disadvantage, poor teaching, frequent change of school, curriculum or medium of instruction, bad home environment or faulty school policies which can explain the poor academic level" (Venkatesan \& Swarnalatha, 2013). Children with LD invariably fail to achieve school grades commensurate with their intellectual potential (Shaywitz, 1998). This connotes a discrepancy factor: a severe discrepancy between the child's intellectual ability and his achievement on paper (John, 2010). If LD remains undetected, it results in chronic poor school performance, detention and dropping out of schools.

\footnotetext{
${ }^{1}$ MSc, Psychology (Clinical), Christ University, Bengaluru

${ }^{2}$ Assistant Professor, Christ University, Bengaluru
} 
This may often lead to these children losing their self-esteem, developing withdrawn or aggressive behaviour, anxiety, depression and at times even anti-social behaviours (Karande, 2008). Children with LD in comparison to typically developed children reported poorer emotional being, lower self-esteem and satisfaction in their relationships with family and friends (Ginieri-Coccossos, et al.,2011)

\section{Quality of Life}

Health related quality of life(HRQOL) as a multidimensional measure can be defined as an individual's satisfaction or happiness in various life domains that affect or are affected by health(Evans, as cited in Michel, Bisegger, Fuhr \& Abel,2009).Disability can have a major impact on the development of an individual physically, emotionally, interpersonally and socially. It's only in the recent times, that rehabilitation looks at improving the overall functioning of the individual therefore improving the quality of life. Karande \& Venkataraman (2012), found large deficits in the areas of social exclusion, emotion, limitation, treatment, and independence, a medium deficit in social inclusion, and a large deficit in the self-perceived health-related quality of life of Indian children with specific learning disabilities.

\section{Parental Practices}

Parental practices and child rearing styles have been linked to mental health and quality of life in various researches. Parental practices are different from parental styles, even though the two have been used interchangeably. According to Darling \& Steinberg (1993), parenting practices are defined as specific behaviours that parents use to socialize their children. In contrast, Darling and Steinberg (1993) define a parenting style as the emotional climate in which parents raise their children

\section{Parental practices: Involvement and autonomy support}

Autonomy or self-regulation has been linked to achievement and, the significant goal of every educational setting is to provide an environment to the child which encourages autonomy and builds the capacity to be self-regulating with respect to one's behaviour and learning process. Keeping the Self Determination theory behind, Grolnick and Ryan(1991) proposed that autonomy support and involvement, are the two correlates of parenting which has found its effect on child development. The parenting environment acts as a resource to promote the inner resources of the child. Studies have shown ways in which students achievement can be enhanced and also the ways it can be hampered in the school and home environments.In these studies two dimensions have been shown to be important for facilitating the inner resources of the childinvolvement versus non-involvement and autonomy support versus control. According to Wang \& Sheikh-Khalil (2014), parental involvement improves academic and emotional functioning among adolescents and also seems to predict adolescent academic success and mental health both directly and indirectly through emotional and behavioural engagement. Autonomy support refers to the active support of the child's capacity to be self-initiating and autonomous (Ryan, Deci, Grolnick, \& La Guardia, as cited in Joussemet et al.,2008). The importance of autonomy 
support claimed by the self-determination theory of parenting in developing and promoting healthy internalization and adaptation is supported by studies. Research has found that children with parents who were autonomy supportive were highly self-regulated, had self-reported competence and displayed fewer adjustment problems at school than those children whose parents were highly controlling (Grolnick \& Ryan, 1986).Grolnick, Ryan \& Deci (1986), postulated a process model, linking the parenting environment and ways in which it promoted the child's inner resources. They hypothesised that the child's perceived parental practices are instrumental in foretelling the child's inner motivational resources which promotes development.

\section{Self-determination theory and disability}

Self-determination is the result of the dynamic interplay among an individual's characteristics and the opportunities and expectations presenting in his or her environments (Wehmeyer, Abery, Mithaug, \& Stancliffe, 2003). The field of disability affirms the importance of the family in developing children's self-determination, and the limited research that exists in this area focuses mostly on specific practices that parents can employ in order to do so (Shogren \& Turnbull, 2006).

Disability can have a profound effect on the child rearing practices that parents involve in, since a child's disability can be very stressful to the parents. Parents of children with a developmental disorder exhibited less positive involvement, less consultation-accompany style, and more rebukes, and felt more difficulty with handling their children(Nakajima, 2012).

Previous studies show how children with LD lag in the areas of emotional well-being and selfesteem. There have also been studies which look into the parent-child relationship in children with LD. However, there are research gaps in establishing direct links between parental practices and quality of life of children with LD. Even though there are research studies that used SDT to focus on developing skills in a child with disability, only limited amount of studies focus on building self-determination for children with disabilities within the home environment. Despite having difficulties at school and academics, if a child with LD is supported and a positive environment is established at home, the child may find ways to create a better life for himself by being able to do what he aspires. This may also be instrumental in bringing out hidden talents in the child and possibly create a life that merges the child's talent and career.

\section{OBJECTIVES}

1. To determine the QoL among children with learning disabilities.

2. To study the relationship between parental practices and quality of life in children with learning disabilities.

3. To determine the gender differences in the quality of life of children with learning disabilities.

4. To understand the differences in parental involvement and parental autonomy support based on gender of the child with learning disabilities 


\section{METHOD}

The present study used the quantitative research framework. The two groups of gender, i.e. boys and girls were taken as the independent variable while Perceived parental involvement, parental autonomy support and overall QoL score was considered as the dependent variable. The targeted population in the study was children with learning disability who are presently studying in Karnataka. The sample consisted of 60 children between the ages of 9 and 12, with learning disabilities, of which 30 were girls and 30 were boys.

\section{HYPOTHESES}

H01: There is no significant relationship between the perceived parental involvement and the QoL of children with LD.

H02: There is no significant relationship between the perceived parental autonomy support and the QoL of children with LD

H03: There is no significant difference in the parental involvement between boys and girls with LD

H04: There is no significant difference in parental autonomy support between boys and girls with LD

H5: There is a significant difference in the overall quality of life between boys and girls with LD

\section{TOOLS}

1. Socio-Demographic Details Form

2. Perception of parents scale (child version), Grolnick,W.S., Ryan, R.M. \& Deci, E.L. (1991) was used to assess the perceived parental involvement and perceived parental autonomy support.

3. KINDL (R), Ravens-Sieberer, U. \& Bullinger, M. (1994) was used to assess the quality of life of children with LD.

\section{PROCEDURE}

After Receiving The Authorization Form From The Parents Through The Consent Form, The Data Collection Procedure Was Initiated. The Questionnaires and demographic details form was administered individually to each child separately. The KINDL(R) QoL questionnaire and the Perception of parents scale was then administered by reading out each item and options provided for each item. The mother or the father subscale was administered based on who the primary parent in the family was. Independent sample t-test was used to study the difference in the variables between the two groups of children, i.e. males and females. Pearson's Product Moment Correlation method and spearman correlation method was used to analyze the relationship between the perceived parental practices and the different dimensions of quality of life in the two groups of children and further multiple regression was used to understand the strength of the relationship. 


\section{RESULTS}

The descriptive statistics indicated that the global QoL of the sample was 70 percentage on an average, even though domains of self-esteem and school revealed to be much lower than the other domains. The descriptive statistics of the parental practices further revealed that the parents as perceived by the child, engage more in involvement than in autonomy support.

At the inferential level, there was a The results indicated that there is no significant relationship between perceived parental involvement and global QoL, but showed a significant relationship on the family domain $(r=.285$ at $\mathrm{p}=.027)$ only.Hence, the null hypothesis was accepted.

Further, the perceived parental autonomy support had a significant relationship with the self esteem $(r=.374$ at $\mathrm{p}=.003)$ and family domains $(\mathrm{r}=.285$ at $\mathrm{p}=.027)$ of QoL, in addition to the global QoL( $\mathrm{r}=.382$ at $\mathrm{p}=.003)$, which implies that the second null hypothesis was rejected. However, the third and fourth hypotheses were accepted since the results showed no significant gender difference in the perceived parental involvement and autonomy support of children with LD. Finally the fifth hypothesis was rejected since the results indicated that there was no significant gender difference in the QoL of children with LD.

Table 1

Correlation to show the relationship between parental autonomy support and QoL

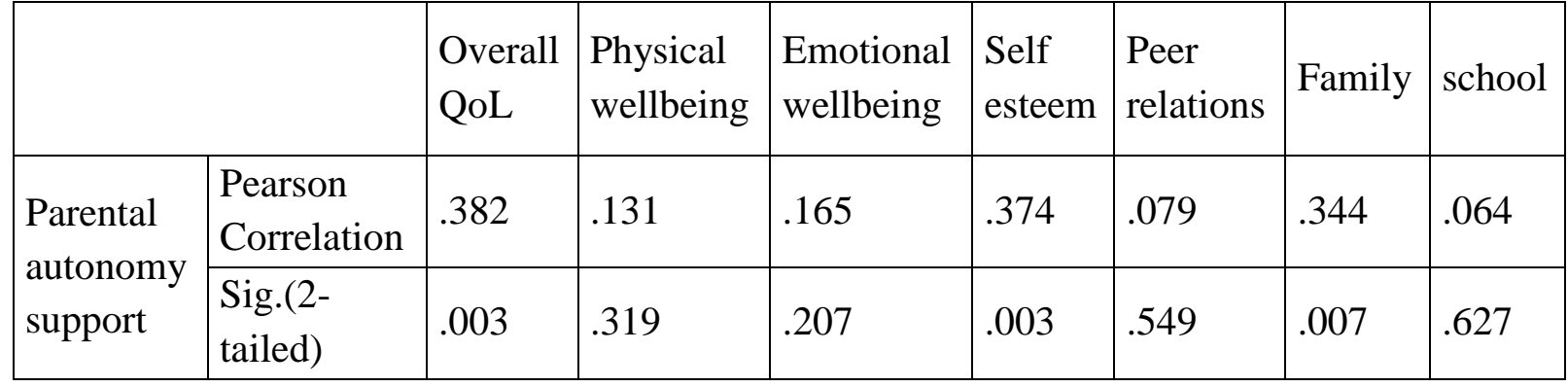

Table 2

Multiple regression showing perceived parental autonomy support as the predictor of QoL

\begin{tabular}{|l|l|l|l|l|l|l|}
\hline Model & $\begin{array}{l}\text { Variables } \\
\text { Entered }\end{array}$ & $\beta$ & $\mathrm{t}$ & $\mathrm{R}$ Square & $\begin{array}{l}\text { Adjusted } \mathrm{R} \\
\text { Square }\end{array}$ & $\mathrm{F}$ \\
\hline 1 & $\begin{array}{l}\text { Overall } \\
\text { QoL }\end{array}$ & .361 & 3.072 & .132 & .117 & $8.798^{* *}$ \\
\hline 2 & Self esteem & .309 & 2.679 & .140 & .125 & $9.435^{* *}$ \\
\hline 3 & Family & .382 & 2.638 & .217 & .189 & $7.895^{* *}$ \\
\hline
\end{tabular}


Multiple regression showed that perceived parental involvement is a significant predictor of QoL on the family domain, and perceived parental autonomy support is a significant predictor of QoL on domains of self esteem $\left(\mathrm{R}^{2}=.140, \mathrm{~F}=9.435, \mathrm{p}<.05\right)$ and family $\left(\mathrm{R}^{2}=.217, \mathrm{~F}=7.895\right.$, $\mathrm{p}<.05)$ in addition to the global $\mathrm{QoL}\left(\mathrm{R}^{2}=.132, \mathrm{~F}=8.798, \mathrm{p}<.05\right)$.

\section{DISCUSSION}

In conclusion of the over all findings of the research, the following things needs to be high lightened:

Firstly, the QoL of children with LD suffers considering their disability and the literature in the past has proved the same. According to a study conducted by Chapman (1988), the findings show that LD students have lower self-concepts than non-handicapped students. Greater decrements occur for academic self-concept than general self-concept. The literature in this area is contradictory to the findings of this study. According to Wang \& Sheikh-Khalil (2014), parental involvement improves academic and emotional functioning among adolescents and also seems to predict adolescent academic success and mental health both directly and indirectly through emotional and behavioural engagement. The significant relationship between perceived parental involvement and only the family domain of QoL could be justified by the fact that parents may be involved in their child's life but may not have involved themselves in academic related activities, thereby contributing to the results obtained. According to Desforges and Abouchaar (2003), it is found that parental involvement has a large and positive effect on the outcomes of schooling, an effect that is "bigger than that of schooling itself". Therefore, it is important for parents to involve themselves in the academics, by sitting down with their child everyday and helping the child learn using other techniques which make of the concepts behind the lesson and not just theory.

Secondly, the significant relationship between perceived parental autonomy support and the QoL on domains of self-esteem and family, in addition to global QoL can be justified by the selfdetermination theory which positively links parental autonomy support to the global well-being variables, because behavioural regulation behind the autonomous motivation involves having a more integrated perception of the self, supportive of one's aspirations toward psychological growth and development (Ryan \& Deci, 2008). The SDT focuses on examining conditions that "elicit and sustain" intrinsic motivation which, by its nature, exists without any intervention. And hence, parental autonomy support could be one of those factors which can sustain intrinsic motivation of the child, therefore contributing to self determination in children with LD. The results of the study hence showed that perceived autonomy support can be a significant predictor of global QoL, self-esteem and family relationships of children with LD.

Thirdly, there were no significant gender differences in the perceived parental involvement and autonomy support of children with LD. This possibly could be due to the fact that the learning 
disability itself acts a big factor influencing the parental practices and gender may not have significantly contributed to the QoL.

Finally, there showed no significant gender difference in the QoL in the sample. According to a study by Michel, Bisegger, Fuhr\& Abel (2009), even though girls and boys had similar HRQoL at a younger age, girls' HRQoL started to decline than that of boys with increasing age. Hence, the results could be explained by the fact that the age group taken into consideration in the present study was 9-12 years and studies show that there have been significant gender differences in QoL as age increases, and the QoL starts to decline only after the age of 12.

To conclude, the present study shows the contributing factor of parental autonomy support in predicting the quality of life of children with LD. This proves that self-determination theory could be applied to children with learning disabilities as well and the outcomes could be remarkable. Hence, self-determination should be encouraged in children LD and the causal agents behind this self-determination behaviour should also be promoted. Parents should be made aware of the advantages of using autonomy support in the home environment and the primary goal of every parent of a child with LD should be to see their child flourish in any desired area and engage in behavioural autonomy, self-regulated behaviour and psychological empowerment.

\section{IMPLICATIONS}

From the results obtained in the study, the following implications can be drawn:

The most important implication of this study is that parental autonomy support should be encouraged in parents of children with LD. Parental autonomy should be included as a major factor when designing parental caregiving programs for children with LD and the findings could be incorporated when psychologists counsel parents of children with LD. Further, parents should be advised to involve themselves in the child's academics, by sitting down with their child every day and help the child learn using other techniques which make of the concepts behind the lesson and make it fun. It is important here to stress that a child spends a lot of his time at home with the primary parent and it is this primary parent who can be instrumental in intervening in the child's academic life than anyone else.

Next, even though inclusive education has been adapted in schools, it should be seen to it that the typically developed children do not involve in bullying and teasing children with LD, since the present study shows a marked deterioration in self esteem. The respective class teachers should pay attention to the classroom behaviour around children with LD and should encourage acceptance and friendship between the typically developed children and children with LD.

Finally, every school must have a trained mental health professional or a special educator who can address these issues professionally and help children with special needs to actively be a part of the school related activities and thereby preventing the hindering of development. 


\section{LIMITATIONS}

The present study encountered some limitation which were inevitable and could not be avoided. The most important of them all is that the sample considered in the study is very specific population from only two cities of Karnataka. Second, the sample consisted of children with different kinds of specific learning disabilities and did not consider only one specific learning disability due to the time restrain and difficulty of finding such a specific sample. Certain specific learning disabilities could have contributed more than the rest towards the QoL of the sample. Third, the age group of the sample considered is 9 to 12 years of age. It might be possible that the younger children would not have had an understanding of their parental involvement and autonomy support despite having explained every item on the questionnaire to them. Finally, in the present study considers the parental practice of only one of the parents who is the primary caregiver and does not include both the parents. Hence, the study does not consider both the parents into the picture. The families where the father was the primary parent could have affected the QoL of children, since studies show that there is marked difference in the home environment and nurturance of the child, when compared to the families where the mother was the primary parent.

\section{REFERENCES}

Chapman, J. W. (1988). Learning Disabled Children's Self-Concepts. Review Of Educational Research, 58(3), 347-371

European KIDSCREEN group.(2009). KIDSCREEN-52 (long version) - kidscreen.org. Retrieved from http://www.kidscreen.org/english/questionnaires/kidscreen-52- longversion/

Darling, N., and Steinberg, L. (1993).Parenting style as context: An integrative model.Psychology Bulletin, 113, 487-496

Desforges, C., \&Abouchaar, A. (2003).The impact of parental involvement, parental support and family education on pupil achievement and adjustment: A literature review. London: Department for Education and Skills

Ginieri-Coccossis, M., Rotsika,V., Skevington,S., Papaevangelou, S., Malliori, M., Tomaras, V., Kokkevi, A. (n.d.). Quality of life in newly diagnosed children with specific learning disabilities $(S p L D)$ and differences from typically developing children: A study of child and parent reports. Retrieved from http://www.ncbi.nlm.nih.gov/pubmed/22372869

Grolnick, W S., Ryan, R. M., and Deci, E. L. (1991). Inner resources for school achievement: Motivational mediators of children's perceptions of their parents. Journal of Educational Psychology ,83, 508-517

Grolnick, W. S., Deci, E. L., \& Ryan, R. M. (1997). Internalization within the family: The self- determination theory perspective. In J.E. Grusec\& L. Kuczynski (Eds.), Parenting and children's internalization of values: A handbook of contemporary theory, (pp. 135-161). New York: Wiley 
Hollar, D. (2012). Handbook of children with special health care needs. New York, $\quad$ NY: Springer

John, P. (2010). Learning and other developmental disorders in India.Indian Journal of

$$
\text { Psychiatry, 52(1), 224-228. Retrieved from }
$$
http://www.ncbi.nlm.nih.gov/pmc/articles/PMC3146230/

Joussemet, M., Landry, R., \&Koestner, R. (2008).A Self-Determination Theory Perspective on Parenting.Canadian Psychology-psychologieCanadienne, 49(3), 194-200

Karande, S. (2008).Current challenges in managing specific learning disability in Indian children. Journal Of Postgraduate Medicine, 54(2), 75-77. Retrieved from http://www.jpgmonline.com/article.asp?issn=0022-

Karande, S., \&Venkataraman, R. (2012).Self-perceived health-related quality of life of Indian children with specific learning disability.Journal of Postgraduate Medicine, 58(4), 246-254. Retrieved from http://www.ncbi.nlm.nih.gov/pubmed/23298918

Michel, G., Bisegger, C., Fuhr, D.C. \& Abel, T.The KIDSCREEN group. (2009). Age and gender differences in health-related quality of life of children and adolescents in Europe: a multilevel analysis. Quality of life research, 18, 1147- 1157

Nakajima, S., Okada, R., Matsuoka, M., Tani, L., Ohnishi, M., \&Tsujii, M. (2012). Parenting styles of parents of children with developmental disabilities. JapaneseJournal of Developmental Psychology, 23(3), 264. Retrieved from http://connection.ebscohost.com/c/articles/82899699/parenting-styles-parentschildren-developmental-disabilities

Ryan, R. M., \& Deci, E. L. (2008). Self-determination theory and the role of basic psychological needs in 24 personality and the organization of behavior. In O. P. John, R. W. Robbins, \& L. A. Pervin (Eds.),25 Handbook of Personality: Theory and Research (pp. 654678). New York: The Guilford Press

Shaywitz, S. E.(1998).Dyslexia.N Engl J Med, 338(30),7-12

Shogren, K. A., \& Turnbull, A. P. (2006). Promoting self-determination in young children with disabilities: The critical role of families.Infants \& Young Children, 19(4), 338

Thapa, K., Aalsvoort, G. M., \&Pandey, J. (2008).Perspectives on learning disabilities in India: Current practices and prospects. Thousand Oaks: Sage Publications

Venkatesan, S.\&Swarnalatha, G.R. (2013). Problem behaviour and academic grade level performance of adjudicated children with juvenile delinquency. Disability, CBR an Inclusive Development Journal, 24(1), 99-114

Wang, M. T., \& Khalil, S. S. (2014). Does Parental Involvement Matter for Student Achievement and Mental Health in High School? Child Development, 85(2), $\quad$ 610-625

Wehmeyer, M.L. (2005). Self-determination and individuals with severe disabilities: Reexamining meanings and misinterpretations. Research and Practice for Persons with Severe Disabilities, 30, 113-120

Wehmeyer, M.L., Abery, B., Mithaug, D., \&Stancliffe, R. (2003). Theory in self- determination: Foundations for educational practice. Springfield, IL: C.C. Thomas 